\title{
Retraction Note: Sichuan mountainous environment and urban planning based on image dehazing algorithm
}

Wei Zhu ${ }^{1}$

Published online: 6 December 2021

(c) Saudi Society for Geosciences 2021

Retraction Note to: Arabian Journal of Geosciences (2021) 14: 1829 https://doi.org/10.1007/s12517-021-08125-9

The Editor-in-Chief and the Publisher have retracted this article because the content of this article is nonsensical. The peer review process was not carried out in accordance with the Publisher's peer review policy. The author has not responded to correspondence regarding this retraction.

The original article can be found online at https://doi.org/10.1007/ s12517-021-08125-9.

Wei Zhu

zhuwei121815@163.com

1 College of Architecture and Urban-Rural Planning, Sichuan Agricultural University, Chengdu 611830, Sichuan, China 